\title{
8 \\ Can recognition of ecosystem services help biodiversity conservation?
}

Saul Cunningham

\section{Key lessons}

- Ecosystem services thinking explicitly brings farmers and their activity into the framework for decision-making and provides a model communicating the benefits of nature conservation that is effective for some audiences.

- Communicating the benefits of ecosystem services to landholders can promote the advantages of nature conservation actions in their landscapes, increasing adoption and community support.

- We should not assume that ecosystem services and biodiversity conservation always pull in the same direction for land use decision-making.

- Ecosystem services thinking can help to identify stakeholders and beneficiaries in a way that improves policy design.

- Management to improve ecosystem services sometimes requires a deeper understanding of ecosystems than we currently have. 
Nature conservation policies have increasingly invoked ecosystem services as part of their rationale. What were formerly biodiversity polices are now increasingly communicated as policies for biodiversity and ecosystem services. Views on this shift range from those who argue that ecosystem services thinking is not particularly useful to conservation policy (e.g. Srivastava and Vellend 2005) through to those who argue that the vision is beginning to have real impact (e.g. Daily et al. 2009). Agri-environment schemes are particularly pertinent in this debate, because they target conservation outcomes in productionoriented landscapes. In this chapter, I examine the extent to which incorporating ecosystem services concepts into policy can affect both the targeting of outcomes and encouraging uptake and engagement in agri-environment schemes.

\section{Ecosystem services thinking}

The essential feature of ecosystem services thinking is to explicitly focus on the values that people derive from nature, unashamedly placing humans at the centre of things. In this way it contrasts to philosophies that emphasise the inherent values of nature, in particular the idea that nature has a right to exist, or that it has an intrinsic value that humans should act to preserve. The boundary between these perspectives can be messy because some ecosystem services frameworks include cultural values. Rather than being drawn into the literature on definitions, here I will use 'ecosystem services' thinking to denote frameworks that put more emphasis on the ways in which nature serves people with things we use (e.g. food and water) or processes that benefit us (e.g. crop pollination, pest control, nutrient cycling). This is in contrast with classical biodiversity conservation thinking, which aims to maximise the preservation of species and genetic diversity.

Combining ecosystem services thinking with biodiversity conservation thinking is relatively simple if the two are tightly linked. If protecting biodiversity is the best route to protect ecosystem services, then the two goals would appear to be extremely compatible. Sure enough, the pattern from extensive reviews of the literature indicate that, in general, more diverse communities tend to support better ecosystem services (e.g. Cardinale et al. 2006), especially if one considers stability 
over time in the assessment (simplified systems might have high levels of provision in some circumstances, but do not respond well to perturbation).

One fundamental rationale for adopting a nature conservation strategy hinges on the idea of protecting these ecosystem services; in this way, the ecosystem services perspective is closely aligned with the idea of sustainability. However, it is not always the case that the goals of biodiversity conservation and ecosystem services protection are always and everywhere in step (Macfadyen et al. 2012). If, for example, one were to assess a landscape and design a system of protected areas to maximise conservation of biodiversity, and then compare it with a system that optimised for water yield, carbon sequestration, and pest control (three example ecosystem services), one would no doubt produce different protected area networks. This is because, at the landscape scale, a focus on species conservation pulls in different directions to a focus on services, and one ecosystem service might pull in a different direction to another.

\section{Ecosystem services in agricultural landscapes}

Conservation goals and strategies depend on the landscape in question. Agricultural landscapes are characterised by significant historical loss of biodiversity and great emphasis on utilitarian production values (i.e. the provision of food and fibre). It is in this context that ecosystem services thinking will be most likely to influence the uptake of conservation actions and the design of strategies. Indeed, pure biodiversity-focused strategies will often downgrade the relevance of conservation in agricultural landscapes, compared with other landscapes which are less modified by people, because much native biodiversity is already lost. It is important, though, to recognise that ecosystem services are relevant to farmers in three quite distinct ways (see Figure 8.1). First, farmers manage their land to provide one of the key ecosystem services to broader society (i.e. food and fibre). Protection of this service means maintaining farming in the landscape. Second, agricultural practice requires the support of a raft of ecosystem services. The benefit of these services flows primarily to the farmer, and second to society that uses the food and fibre. 
Third, farmers have the potential to manage their land for a range of ecosystem services for the benefit of broader society rather than for themselves - by sequestering carbon and thereby reducing the risk of climate change, for example. If ecosystem services thinking is going to be used to shape agri-environment schemes, the different kinds of benefit flow described in this framework need to be understood by policymakers.

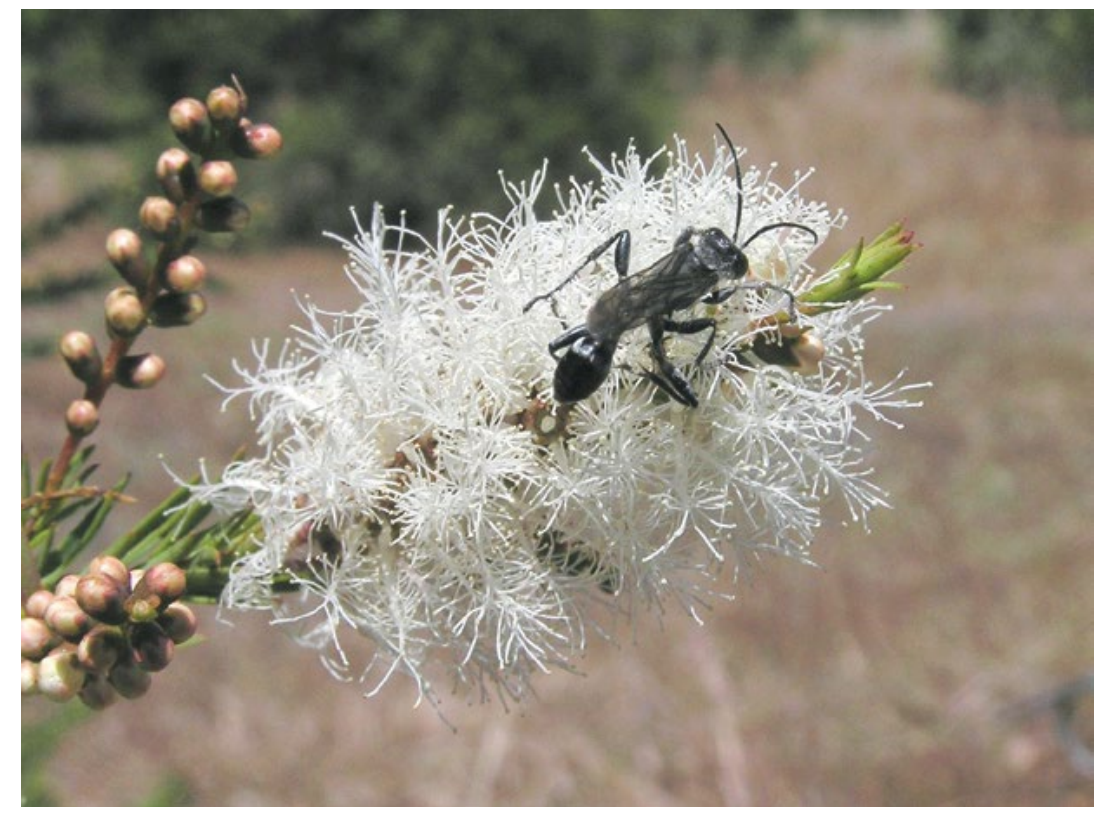

Figure 8.1: Wasps help to control pests in agricultural systems and pollinate crops and native species.

Source: Photo by Saul Cunningham.

Reflecting on the fact that farmers provide society with food and fibre is important in terms of validating the role of agriculture in the landscape, and recognising the value of that land use to society. But it does not follow that all agricultural practice is justified by the need for food and fibre. Some conservation planning exercises include production in a cost-benefit analysis, asking if the cost of a conservation action (in terms of lost production) is justified in terms of the benefit (in terms of nature saved) (e.g. Hodgson et al. 2010). This approach leads into the land sparing/land sharing spectrum of choices, discussed in Chapter 9. The pragmatic reality is that land use decisions will always be influenced by use values, and so the 
production side of the equation will always affect the decision, even if it is not in a formal cost-benefit analysis. The effectiveness of payments to landholders to effect land use change will, of course, depend on the production values of land.

\section{Recognising and communicating benefits}

Ecosystem services that support agricultural activity can be considered private benefits (see chapters 14 and 18) because there is a direct economic pay-off if farmers increase them. For example, if protection of native grasslands around a field margin increases pest control and crop pollination on farm, this would be a private benefit to the farmer, albeit linked to nature conservation. But there are great challenges in using these kinds of benefit to motivate land use change (see Chapter 12). In most cases, farmers will not have enough information to guide practice change to exploit these benefits. Often the benefit of improvement in one particular ecosystem service will not be great enough to justify the cost (e.g. lost area of production). The benefit may also require land use changes on a scale beyond the area of a single farm, and therefore beyond the scope of a single landholder's decision-making. For example, benefits of natural pest control might be influenced by non-crop vegetation that is kilometres away, and therefore require cooperation among neighbours to achieve. There may also be a lot of uncertainty around the reliability in supply of the ecosystem service over time and space compared with the relative certainty associated with agronomic inputs, invoking new risks.

For these reasons, the use of ecosystem services strategies to increase the adoption of on-farm nature conservation requires landholders and policymakers to have a high level of understanding of the system, and an honest assessment of the economic challenges facing farmers. In many circumstances, ecosystem services benefits may only partially offset the costs of nature conservation practices. The nature and magnitude of costs and benefits are likely to vary according to the economic and biophysical characteristics of the type of production system (e.g. annual cropping versus grazing). Benefits are likely to be greatest when combined with strategic assessment of the productivity of different parts of the farm, so that poor areas for production are 
relinquished but ecosystem services benefits are realised. Public policy has a potentially significant role in helping farmers to make the changes that lead to these private benefits from ecosystem services.

Ecosystem services that farmers, as land managers, provide to society can be considered public benefits (see Figure 8.1). Farmers are unlikely to make costly changes to farm practice simply to support benefits to broader society, unless they are encouraged by incentives (see Chapter 4). In most cases, however, land use change in the interest of public benefit (such as management of streamside vegetation to support clean water downstream) will also influence nature conservation outcomes and sometimes even private benefits, such as shade and shelter for stock. In practice, one needs to assess all these dimensions. One of the strengths of the ecosystem services paradigm is in making sense of these private and public benefits in a way that can support cost-effective investments.

The social acceptability of land management action is likely to be greatest if advocates are effective in communicating the multiple benefits - private benefits, public benefits, and nature conservation benefits - associated with the change. Participation in native vegetation management programs in Australia was motivated by a mix of drivers, including ecosystem service benefits to the farm along with nature conservation (see Chapter 12). Payments for stewardship or, for example, carbon farming will attract some landholders who are sympathetic to the program, even if the payments are modest. But one can expect wider acceptance of these programs (even at the same payment level) if there is an understanding that the land use changes will provide private ecosystem services benefits to the farmer in addition to the ecosystem service and biodiversity conservation outcomes recognised by broader society (Lin et al. 2013). The idea of recognising these co-benefits is particularly relevant for the relationship between biodiversity conservation and ecosystem services, because while they are not necessarily jointly optimised by the same actions, any given action for one is likely to lead to a marginal benefit in the other, compared to the alternative scenario of no land use change. Well targeted incentives, such as payments for fencing, might play an important role in supporting landholders to take up these opportunities. 


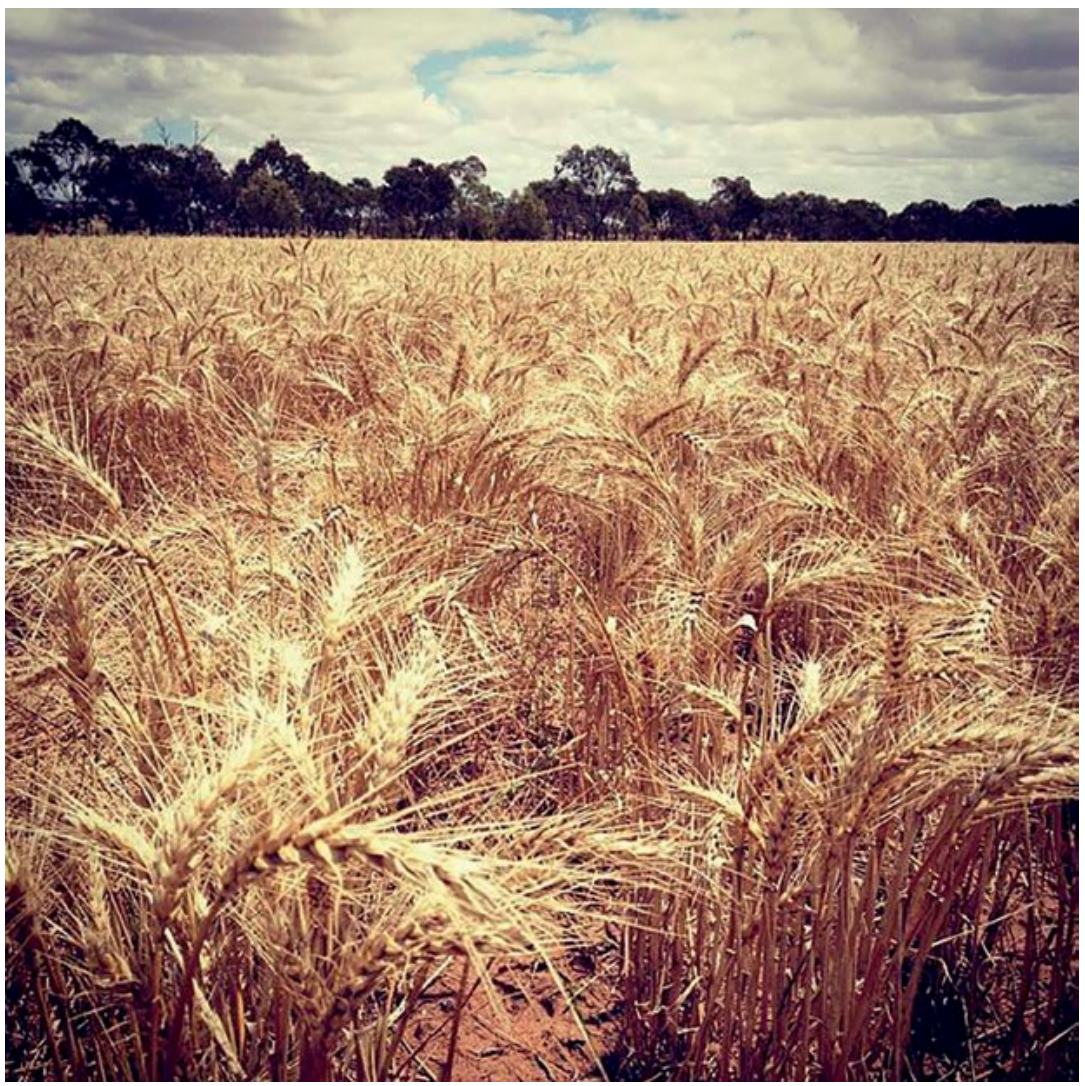

Figure 8.2: A wheat crop amongst bushland.

Source: Photo by Belinda Gibson.

To this point, I have argued that an ecosystem services perspective has the potential to drive better engagement in conservation policies in agricultural landscapes, but also that there are substantial knowledge gaps. In particular, it is difficult to argue that there are benefits to farmers, or even to broader society, unless we have a good understanding of the natural systems we are dealing with. We have enough understanding to promote some general principles that suggest biodiversity and ecosystem service benefits are supported by protection of habitat remnants. For example, conserving patches of native vegetation in agricultural landscapes is known to support crop pollinators (Garibaldi et al. 2011). But it is more challenging to advise a landholder on the specific benefits that can be expected to flow from a given investment in ecological restoration, and by how much 
and under what circumstances these services will improve a farmer's bottom line. The outcome considering multiple benefits is more likely to be positive than that from a single ecosystem service, but also more complex to determine (Olschewski et al. 2010). It is also important to remember that while the ecosystem services perspective promotes engagement with some people, there are others who are put off by the utilitarian perspective of nature. Ecosystem services ideas should be used strategically as a means of communicating some values from nature, not as a replacement to pre-existing frameworks for nature conservation.

\section{Paying for ecosystem services}

A large part of the literature on ecosystem services focuses on economic valuations of ecosystem services and the conceptualising and design of markets or payment systems, so that money flows from the beneficiaries of the service to those who pay the cost of land management. While this has attracted a lot of attention, conservation strategies in Australia have not yet been substantially influenced by payments for ecosystem services programs. In this respect, talk appears to have outstripped action. But this does not mean that ecosystem services thinking has no relevance to nature conservation strategies. Payments for carbon sequestration are still on the political agenda and have the potential to affect nature conservation in some agricultural landscapes. It is wrong to judge the impact of ecosystem services thinking by focusing only on the degree to which payment strategies have been implemented. The best nature conservation strategies should address the sustainability of human well-being, as well as conservation of biodiversity per se, and this broader goal can be guided by ecosystem services frameworks. A focus on the utilitarian values of nature is required to get the best engagement from the landholders that manage most of the landscape, especially in agricultural landscapes (Goldstein et al. 2012). 


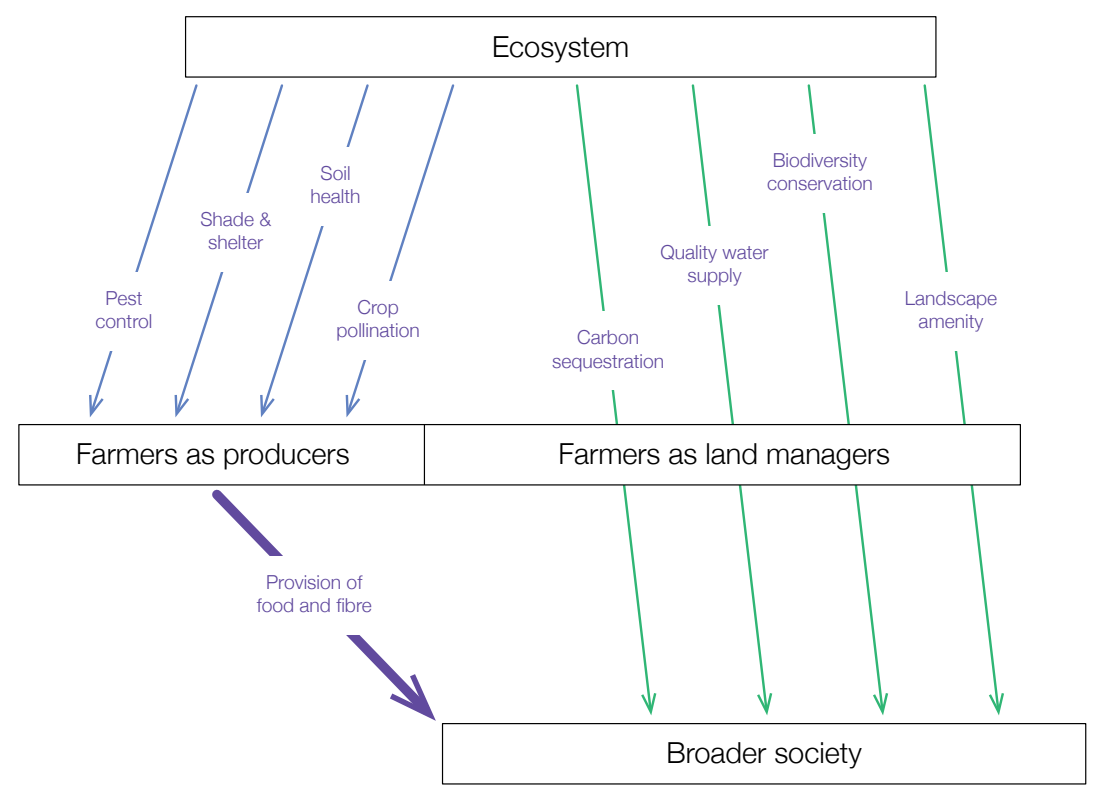

Figure 8.3: This framework highlights ecosystem services that are most relevant to farmers.

Source: Author's research.

Note: Purple text names ecosystem services that are widely recognised in the general literature. The arrows indicate how these services flow from ecosystems to human society in general, and what role farmers have in this flow. The framework deliberately separates two different roles that farmers play: their primary role as producers, and their secondary role as land managers. The large purple arrow highlights the obvious major ecosystem service: the provision of food and fibre. The blue arrows highlight the services that ecosystems provide to farmers, supporting their production activity (i.e. private benefits). The green arrows identify services that ecosystems provide to society in general (i.e. public benefits), which farmers can influence substantially in their role as land managers.

\section{References}

Cardinale, B.J., D.S. Srivastava, J.E. Duffy, et al. (2006) 'Effects of biodiversity on the functioning of trophic groups and ecosystems', Nature 443: 989-92.

Daily, G.C., S. Polasky, J. Goldstein, et al. (2009) ‘Ecosystem services in decision making: Time to deliver', Frontiers in Ecology and the Environment 7: 21-8. 
Garibaldi, L.A., I. Steffan-Dewenter, C. Kremen, et al. (2011) 'Stability of pollination services decreases with isolation from natural areas: A global synthesis', Ecology Letters 14: 1062-72.

Goldstein, J.H., G. Caldarone, T.K. Duarte, et al. (2012) 'Integrating ecosystem-service tradeoffs into land-use decisions', Proceedings of the National Academy of Sciences USA 109: 7565-70.

Hodgson, J.A., W.E. Kunin, C.D. Thomas, et al. (2010) 'Comparing organic farming and land sparing: Optimizing yield and butterfly populations at a landscape scale', Ecology Letters 13: 1358-67.

Lin, B.B., S. Macfadyen, A.R. Renwick, et al. (2013) 'Maximizing the environmental benefits of carbon farming through ecosystem service delivery', BioScience 63: 793-803.

Macfadyen, S., S.A. Cunningham, A.C. Costamagna and N.A. Schellhorn (2012) 'Managing ecosystem services and biodiversity in agricultural landscapes: Are the solutions the same?' Journal of Applied Ecology 49: 690-4.

Olschewski, R., A-M. Klein and T. Tscharntke (2010) 'Economic tradeoffs between carbon sequestration, timber production, and crop pollination in tropical forested landscapes', Ecological Complexity 7: $314-19$.

Srivastava, D.S. and M. Vellend (2005) 'Biodiversity-ecosystem function research: Is it relevant to conservation?', Annual Review of Ecology Evolution and Systematics 36: 267-94. 
This text is taken from Learning from agri-environment schemes in Australia: Investing in biodiversity and other ecosystem services on farms, edited by Dean Ansell, Fiona Gibson and David Salt, published 2016 by ANU Press, The Australian National University, Canberra, Australia. 